\title{
Discussion on the Development of Car-Free Carriers in China's Logistics Industry
}

\author{
Junye Zhang \\ School of Logistics, Beijing Wuzi University, Beijing, China \\ Email: 7935822@qq.com
}

How to cite this paper: Zhang, J.Y. (2019) Discussion on the Development of Car-Free Carriers in China's Logistics In-dustry. Open Journal of Business and Management, 7, 828-836.

https://doi.org/10.4236/ojbm.2019.72056

Received: March 26, 2019

Accepted: April 13, 2019

Published: April 16, 2019

Copyright (C) 2019 by author(s) and Scientific Research Publishing Inc. This work is licensed under the Creative Commons Attribution International License (CC BY 4.0).

http://creativecommons.org/licenses/by/4.0/

\section{(c) () Open Access}

\begin{abstract}
Under the current "Internet + Logistics" model, the "car-free carrier model" has also emerged as a new thing. This model is not simply a logistics vehicle that is not equipped with transport vehicles. Units or individuals, these people are not engaged in the corresponding transportation business, but simply the transportation organization, the sorting of goods and the choice of transportation methods and routes. They mainly obtain the corresponding difference income by "wholesale" for transportation. Its main business objects are mainly principals, carriers, etc. The main workflow is to sign the power of attorney, the dispatch of the waybill, loading, signing and so on. This paper aims to find out the limitations of the development of car-free carriers in China in the logistics industry from the development of car-free carriers in China. Based on the development of car-free carriers abroad and the development experience of non-vessel carriers in China, the corresponding development proposals are proposed.
\end{abstract}

\section{Keywords}

Car-Free Carrier, Logistics, Transportation, Development

\section{Introduction}

In recent years, with the continuous improvement of China's transportation facilities, the volume of transportation and transportation has also increased significantly. According to the relevant research results, the current transportation mileage of China's railways and electrified railways has reached a new high, reaching the second level in the world. The operating mileage after the highspeed rail investment has directly increased to the first place in the world [1]. In the current rapid development of China's economy, the demand for road transportation is also increasing. In order to further meet the basic needs of China's 
road transportation, the transportation industry is also developing rapidly in a synchronized manner, gradually transforming from passive development in the past to state-led development. In the current development process, the improvement of the transportation system can further promote the development of China's transportation industry, thereby alleviating the current tensions in the transportation industry. Therefore, the improvement and development of the integrated transportation system is the future development trend.

In 2013, China proposed the "One Belt, One Road" development strategy. In the following years, China has made a lot of work in organizing organizations such as the AIIB to develop and implement the "One Belt, One Road" national strategy. The "Belt and Road" policy is mainly to connect the current three continents of Asia, Europe and Africa, and then integrate their resources. When it comes to resource integration, the concept of the current car-free carrier must also be indispensable. The "Car-free carrier" refers to an individual or unit that does not own a vehicle and is engaged in the transportation of goods. At present, the "car-free carrier" itself has a dual identity, which is the main carrier for the shipper; but for the actual carrier, he is also the shipper. Through the Internet's innovative organization model, the car-free carrier has strong resource integration capability and obvious network effect, which promotes the effective integration of transportation market resources, enables resources to be concentrated, and the industry is more standardized, which is conducive to promoting the logistics and transportation industry. Transformation and upgrading can improve the transportation quality of current goods, and thus continuously increase economic benefits.

Current research on car-free carriers is relatively extensive. Chang et al. in order to optimize the transportation resources carried by the car-free carrier and reduce the operating cost, a vehicle-free carrier resource organization optimization model with opportunity constraints was established [2]. Dong made a general overview of the development status of China's car-free carriers and summarized the problems encountered and possible in the development of domestic car-free carriers, and pointed out that the car-free mode itself and China The current "car-carried" is a conflict, which makes it difficult for the current car-free carrier to be recognized by relevant departments and agencies. At the same time, there are still many problems in the current development, such as post-tax and remote locations [3]. Luo also proposed that in the actual operation process, transportation companies obtain transportation resources by purchasing a small number of vehicles or renting vehicles. In the actual operation process, most transportation companies subcontract the transportation business to independent. The car owner to complete, this will further cause the current situation of China's car-free and car-borne mixed operation [4]. Pang pointed out the future development prospects of the current car-free transportation through research and analysis, and then pointed out that the current Chuanhua Logistics is making great strides, and gradually realizes the national network layout. The con- 
struction of the physical highway port platform has improved the quality of the cargo owners and expanded the channels of supply, making the cargo resources more stable and stable. Chuanhua Logistics will integrate all the transportation resources and trunk lines according to the construction of the platform, and build a trunkless network car-free carrier platform [5]. According to the current development policy, Sang pointed out that China should implement the car-free mode of transport under the premise of rapid Internet development. These business models are encouraged by the state and transportation regulatory authorities [6]. Zhang analyzed the development status of car-free carriers [7].

At present, foreign research has begun to bear fruit for the study of car-free carriage. The American Robinson Logistics was formally established in 1905. At the beginning, the company only carried out fruit wholesale. In the case of the US transportation industry striding forward, the company officially entered the field of car-free carrier development. Huang et al. conducted a detailed analysis of American Robinson Company, clearly indicating that the company currently has 110,000 customers worldwide and has 68,000 carriers, but the company does not have a car or a ship. Robinson outsources non-core business to professional companies, such as transportation and warehousing, and only does the company's core business, such as processes, information systems, human resources, etc. Robinson has become the world's largest car-free carrier company. Robinson is worthy of a car-free model. The company does not have a car but serves more than 37,000 customers worldwide. Currently, it has 235 outlets all over the world. Robinson's successful experience provides the development of car-free transportation in China a powerful reference [8]. W Hoffman argues that in North America, where logistics demand is skyrocketing, the car-free carrier model needs to be developed [9].

\section{Overview of the Development of Car-Free Carriers in China}

Car-free carrier itself is promoted on the basis of highly developed Internet, mainly through the Internet to obtain relevant logistics information, and then further integrate these distribution resources and cargo resources to ensure the current cargo resources of these entities. Effective integration with the Internet. For the reduction of intermediate links, and thus promote the efficiency of these resource allocation, and then continuously improve the overall efficiency of work, the cost of logistics subcontracting is further reduced. The car-free carrier mode can achieve "one arrow and multiple sculptures": from the perspective of the cargo owner, it is very important to reduce costs and improve circulation efficiency; from the perspective of the capacity resource owner, the "exploitation" situation of the owner is reduced., to increase the cargo rate, increase profits; on the platform side, can earn a small amount of the difference, mainly to get a large number of users, increase traffic. This is of course the so-called "win-win" in modern management. 
At present, China has announced some car-free carrier pilots. At present, some truck drivers have gradually become accustomed to finding corresponding services on the mobile platform. This platform is what we call a car-free carrier. The release of the list of 28 pilot projects of the first batch of backbone logistics information platforms marks the new era of giving the logistics platform a new mission from the national level, namely, accelerating the resolution of the "information island" and "information chimney" and other long-term constraints on the development of China's modern logistics industry. The problem is to improve the modernization, organization and intelligence of the logistics industry, and create better conditions for deepening the logistics cost reduction and efficiency and promoting the development of the real economy. This marks the rise of the car-free carrier model. Like the cargo pull platform, its business direction is positioned as the same city instant vehicle freight, the cargo owner through the cargo pull platform, can quickly match the nearby truck resources, and get high-quality freight services at low prices, the majority of truck drivers can also rely on cargo pull Pulling quickly to meet customer needs, greatly improving the efficiency of truck utilization, and thus obtaining a more lucrative income return; it is intended to become China's largest vehicle capacity dispatching platform, the largest intelligent logistics information platform and the largest car-free carrier. At the same time, it is also a model project of "Internet + Logistics", traffic big data and energy saving and emission reduction; truck help is China's largest road logistics internet information platform, establishing China's first nationwide source information network and providing platform trucks. Integrated services, dedicated to China's highway logistics infrastructure. These logistics industry network platforms have been able to provide comprehensive freight services. The one-stop logistics transportation service platform has developed into a new development idea for car-free carriers. It is different from the various logistics $\mathrm{O} 2 \mathrm{O}$ platforms that are emerging now. It not only acts as an intermediary, but also aims to solve various kinds of transportation processes. Problems such as driver shipping costs, accident recovery issues, cargo security issues, etc.

At present, it seems that the development situation of China's car-free carriers is optimistic, but the existing problem is the problem of VAT deduction. In general, we believe that car-free shipping is a traditional freight forwarding service. The current national policy is that only those enterprises that have transportation tools can be called the transportation industry, and these enterprises also need to be able to issue professional road transport value-added tax invoices; for example, some of them are used to complete the entire transportation process through outsourcing. It is considered to be a freight forwarder and is not able to issue special VAT invoices required by customers. But customers need invoices with an $11 \%$ tax rate, and we only have to find some other invoices for them. At present, there is a strange development phenomenon after the "reform of the camp". Some companies that actually carry logistics do not have the required $11 \%$ of invoices because they do not have vehicles themselves. Instead, some 
companies that have been affiliated with them have issued the qualification of such invoices further increases the tax burden of current transportation companies. At present, Shanghai has applied for identity certification for car-free carriers, so that they can have the conditions for issuing corresponding VAT. This specific example can also be widely adopted and used by other regions. At the same time, it is still difficult for current car-free carriers to obtain the corresponding operational qualifications for road transportation and the lack of effective transportation guarantee mechanisms. These are all important issues currently facing. In view of the lack of corresponding transportation guarantees, some enterprises have already solved the problem by purchasing commercial insurance for goods. The next step is still to discuss with the relevant insurance companies and then launch insurance services suitable for car-free carriers.

\section{China's Car-Free Carrier Development Constraints}

1) The purpose of the tax rate is not clear.

At present, China's logistics industry still issues a VAT invoice with an 11\% tax rate. At present, the US logistics industry does not need to issue relevant tax invoices. It only needs to pay invoices. This gap in taxes and fees has caused the current cost of China's logistics industry to be much higher than the United States. In the actual development process, China hopes to reduce the cost of the current model through the development and implementation of the car-free carrier model. However, from the perspective of commercial development, this is actually unfavorable for the development of the logistics industry..

2) The industry standardization department is in its infancy and the industry maturity is low.

China is currently in a period of rapid development. The entire logistics market is relatively chaotic, and the standardization process has not yet been formed. The "top design" is zero, and there is almost no standardization. At present, the waiting time for long-distance vehicles is basically maintained at 3 5 days, which also includes waiting for goods and delivery. This severely limits the efficiency of the vehicle. The low maturity of the industry also leads to a decline in the quality of employees, and there is no credit system.

3) The intermediate links in the market are complex.

China has basically no more than 3 billion car-free carriers in the development process, lacking corresponding market-oriented development, and the intermediate links are relatively complicated. From the cargo owner to the last carrier driver, there are multiple subcontracting links in the middle. This creates a common problem in the industry-car-free carriers cannot control the drivers of the terminal.

4) Differences in freight settlement mode.

At present, the settlement period of manufacturing enterprises in developing countries is three months or more, and even six months before settlement and acceptance. Because it lacks a relatively complete credit mechanism, this has 
caused manufacturing companies to start mortgage loans to some logistics companies. The driver side must settle the shipping charges for the month. This has caused a large amount of funds for current car-free carriers to exist in accounts receivable. It is always controversial whether car-free carriers should be labor-intensive or capital-intensive. It is often only possible to make more than three billion projects or contracts through more than one billion yuan. Because of the problem of its own funds, the size of the current car-free carrier company is limited, which makes it difficult to ensure the viscosity of the supplier.

Also, most of the vehicles in China's logistics industry are still in the hands of individual households; there are more Chinese private logistics enterprises and transportation fleets; although China's vast land resources are not balanced, the resources of China's drivers are generally not high, they are still living. Driving; China's cargo owners are not mature, they are not interested in value services, but more important is the transportation price; the current Chinese highway is still in the charging process, there are other types of fines; China lacks clear vehicle standards. Therefore, there is a lack of specific standardization work. These have limited the development of car-free carriers in China.

\section{Suggestions for the Development of Car-Free Carriers in China}

\subsection{Suggestions for Car-Free Carriers Themselves}

The sharing economy is the hottest Internet innovation direction in the moment, and the sharing economy and the freight industry can be more closely linked in the future. The emergence of the sharing economy not only rationally allocates and maximizes the use of idle resources, but also the freight industry joins the shared industry to improve the allocation efficiency of both the supply and demand sides of the freight through a shared model. It is recommended that the existing large freight platforms jointly develop relevant industry standards, stipulate standardized operation procedures, and lead the development of the entire car-free carrier market; the platform guarantees good service and the safety of customer items; the car-free carrier platform needs to improve the driver. The stickiness, avoiding the phenomenon of driver loss and supervising the cargo driver, as long as the driver of the platform belongs to the platform management, unified management of the driver of the terminal, so that the intermediate links of the market are simplified.

\subsection{Suggestions for Car-Free Carrier Legislation}

At present, China's "Road Transportation Regulations" and related "Road Cargo Transportation and Battlefield Management Regulations" have no clear regulations on the management of carriers, which further causes the car-free mode of carriage to be unable to be subject to specific legal supervision. Because of the lack of relevant regulatory systems, car-free carriers have an unfair relationship between outsourced transporters and shippers. Because of the lack of specific 
constraints and regulations, the occurrence of a foreign cargo flight has occurred, which has seriously affected the development of the current road freight market [10].

In the final analysis, the socialist market economy is still the legal economy. In the emerging market of car-free transport, a mature law is needed to fairly and reasonably adjust the rights and obligations between equal subjects, so that the car-free market can move forward in a healthy and orderly manner along the legal track.

1) Relevant legislation should be reasonable.

At this stage, the only criterion for measuring the legitimacy of car-free carriage legislation is whether it is conducive to promoting the development and growth of China's logistics market economy, whether it is conducive to actively and fairly mobilizing and adjusting the most active cargo market. Factors-the cargo and the car and its related parties. Enterprises that are the main players in the economy of the car-free carrier market can exercise their rights independently in accordance with relevant laws and resort to legal protection when rights are violated.

2) Relevant legislation should be stable.

The stability of the current law is crucial. It can ensure a relatively stable social relationship between the current parties, enhance the current legal awareness of people, and further maintain the current development of the car-free carrier market, while promoting the entire market. Form a legal atmosphere. In order to make the legislation related to car-free carriage not only divorced from reality, but also has strong stability, it must make its content advanced and appropriate foresight, reflecting the characteristics of the times.

3) Relevant legislation should be clear.

The so-called clarity means that the content of a law is complete, there is no "gap" between the articles, no overlap, no conflict, the use of words does not produce ambiguity, and has strong operability. The characteristics of clarity are also reflected in the rigor and accuracy of the text. In the current development process, the NVOCC model provides a good example of development, and the establishment of the relevant Maritime Law provides a good foundation. The law has a total of 278 articles of 15 chapters. Because of the specific formulation of its provisions, the Standing Committee of the National People's Congress passed the law and decided not to formulate additional implementation rules. As a latecomer, the car-free carrier should actively study the experience in the formulation of the Maritime Law and fully consider the clarity.

\subsection{Suggestions on Government Related Work}

Interconnection, the current logistics supply and demand itself can further realize more reasonable configuration from some redundant links; network interconnection itself can solve the cumbersome work of current manual entry, thereby effectively reducing labor costs; speeding up the flow of information, en- 
suring business The speed of the process; currently through the use of the mobile Internet, operators can further accelerate information integration and processing capabilities, and liberate productivity.

On one hand, from the perspective of current market development, the implementation of car-free carriers will also have certain negative impacts. Everyone is very happy to see that the policy is properly implemented, and the value of institutional innovation and technological innovation plays a role in guiding the industry to reduce costs or promote industry expansion. On the other hand, if it is forced to provide price cuts, then this will lead to increased competition within the industry, which will effectively affect the profit and order of the entire industry.

Therefore, in the current development process, the development of the Internet and informatization is a double-edged sword. The unfavorable development of the industry is mainly due to the impact of the market, which often causes some large-scale mass incidents. The difference between the freight market and the taxi market is that the taxi market itself pays more attention to the convenience of travel. This is a specific livelihood issue; and the freight itself is closely related to the national economy. All of these require the government to weigh the pros and cons when implementing the New Deal.

According to the "Opinions on Accelerating the Innovation and Development of Car-Free Carrier Logistics for Pilot Reform Pilots" issued by the Ministry of Communications, it is clearly pointed out that the current provincial-level transportation departments should speed up the communication and exchanges with the tax authorities, and implement the specific requirements for the relevant camp reforms as soon as possible. Further guarantee the VAT management and specific regulatory issues faced by these pilot enterprises, and solve the practical problems of enterprise open qualification, VAT management qualification and quota monitoring, regulate the current corporate tax payment behavior, strengthen tax supervision, and prevent tax risk.

\section{Conclusion}

The car-free carrier pilot itself is both an opportunity and a challenge, because in the actual development process, car-free is not the key, and whether there is specific carrier capacity is the foundation of development. In order to promote the development of the current logistics industry, the transportation department also needs to open up the specific policies of the relevant car-free carriers, but whether the enterprise can carry out good operations and operations is itself determined by the enterprise itself. In any case, the implementation of this policy is a good start in itself. In the future, the logistics industry will also usher in a better development trend. The entire logistics industry itself will also undergo major changes. The implementation of the car-free carrier itself has also proposed a good development opportunity. We can boldly predict that with the continuous development of car-free carriage in China, we will gradually enter the decade of new development of the logistics industry. 


\section{Conflicts of Interest}

The author declares no conflicts of interest regarding the publication of this paper.

\section{References}

[1] Li, W. (2014) China's Transportation Industry: Analysis of Problems, Status Quo and Development Trends. Modern Economic Information, 17, 25-30.

[2] Chang, L. and Chen, H. (2016) Research on Optimization of Car-Free Carrier's Capacity Resource Organization. Journal of Highway and Transportation Research and Development, 33, 152-158.

[3] Dong, N. (2011) Car Carrier's Advantage Analysis and Development Suggestions. Communications Standardization, 24, 87-90.

[4] Luo, W. (2016) The Opportunity of "Internet + Car-Free Carrier" Is Coming. China Logistics and Purchasing, 15, 50-52.

[5] Pang, B. (2016) Chuanhua to Build a Trunk Network Car-Free Carrier Platform. China Logistics and Purchasing, 19, 65-72.

[6] Sang, S. (2016) Exploration on the Reform of Driver and Vehicle Management Mode under the Car Carrier Business Model. Modern Economic Information, 25, 58-65.

[7] Zhang, J. (2018) Discussion on the Development of Car-Free Carriers in the Logistics Industry. Market Modernization, 11, 15-17.

[8] Huang, S. and Li, H. (2016) On the Necessity and Feasibility of the Development of Car-Free Carrier in China. Journal of Transport Management Institute Ministry of Transport, 1, 17-20.

[9] Hoffman, W. (2006) UTi Acquires Truck Broker. Traffic World, 270, 86-94.

[10] Dong, N. (2011) Vigorously Promote the Development of the Car-Free Shipping Market. Transportation Enterprise Management, 12, 67-70. 